\title{
The Short Term Cardiovascular and Pulmonary Responses to Exercise in Young Adults
}

Ambreen Khalid, Adeela Shahid, Farhat Aitazaz.

Department of Physiology, Shalamar Medical \& Dental College, Lahore.

\begin{abstract}
Background: Impaired cardiovascular and respiratory functions are associated with increased mortality and morbidity. Exploration of the relation between physical activity and cardiovascular and respiratory functions can help in understanding the mechanisms of how physical activity improves a person's quality of life.

Objectives: To investigate the post exercise cardio-respiratory response of normal healthy adults and to determine if there are gender differences in the post exercise cardio-respiratory response.

Methods: A cross-sectional study was conducted on $1^{\text {st }}$ and $2^{\text {nd }}$ year MBBS students of Shalamar Medical and Dental College in the department of Physiology. Measurement of Pulmonary functions and recording of ECG was done by using Power LAB before and after exercise. Statistical analysis was done on SPSS version 21, student $t$ test was applied and $p$ - value $<0.05$ was considered statistically significant.

Results: The respiratory rate, respiratory minute volume and tidal volume increased while oxygen saturation decreased significantly after exercise. Heart rate increased significantly in post exercise period. The pre exercise systolic and diastolic blood pressure increased significantly after exercise. There was a significant post exercise increment in diastolic pressure in males than in females. QT was significantly decreased in post-exercise period in female subjects.

Conclusion: The respiratory parameters changed significantly after exercise. Heart rate and blood pressure increased significantly both in male and female subjects. QT interval decreased significantly only in females; however, changes in PR interval and QRS complex were not significant.
\end{abstract}

Key Words: Post- Exercise, Cardiovascular changes, Respiratory changes, Healthy adults.

\section{INTRODUCTION}

Exercise is considered a tool for testing the physiological responses and physical proficiencies of an individual for confirmation of good health status and well-being. It improves the endurance, and enables a person to withstand stress and survive in the circumstances where it is difficult to survive otherwise ${ }^{1}$. Another tool for the assessment of optimum pulmonary health status is pulmonary function test which predicts overall survival rates in both genders. Pulmonary function tests include the forced expiratory volume (FEV1), which is the amount of air that is exhaled by a person in first second, and the forced vital capacity (FVC), which is the maximum amount of air that a person exhales after taking the deepest breath ${ }^{2}$. Treadmill tests and spirometric tests are important measurements for evaluating cardiovascular and respiratory functions. The positive relation between physical activity and a treadmill test is considered more reliable than that between physical activity and spirometric parameters $^{3}$. The rate of post-exercise cardio deceleration is used as an index of cardiac vagal reactivation. Analysis of heart rate variability (HRV) and complexity can provide useful information about autonomic control of the cardiovascular system ${ }^{4}$. The Blood pressure (BP) response to exercise is an important marker of cardiovascular disease (CVD) risk and cardiovascular mortality. BP changes during submaximal exercise represents a physiological response to low-to- moderate daily physical activity which can be closely correlated with ambulatory BP, mean daily BP and end-organ damage. Walking often represents the most feasible and accessible form of isotonic exercise which helps in weight management ${ }^{5}$. A short period of electrocardiographic recording during hyperventilation is also valuable for identifying 
changes resulting from hyperventilation ${ }^{6}$. Impaired cardiovascular and respiratory functions are associated with increased mortality and morbidity ${ }^{3}$. Exploration of the relation between physical activity and cardiovascular and respiratory functions can help in understanding the mechanisms of how physical activity improves a person's quality of life. Hence, this study was executed to appraise the effect of exercise on cardiac and respiratory variables in young and healthy students at Shalamar Medical and Dental College.

\section{MATERIALS AND METHODS}

\section{Settings}

This cross sectional study was conducted at the Shalamar Medical and Dental College (SMDC) in the department of Physiology. Ethical approval was taken from institutional review board. The study was completed in one year.

\section{Subjects}

The study was conducted on 50 students of 1 st and 2nd year MBBS. The age of these participants ranged from 19-20 year. Convenient sampling technique was used.

\section{Methods}

Measurement of Pulmonary functions and recording of ECG was done by using Power LAB. Following cardio-respiratory parameters were chosen for the study, respiratory rate, oxygen saturation, tidal volume, minute respiratory volume, heart rate, systolic and diastolic pressure, PR, QT interval and QRS complex of ECG. The study was approved from the Institutional review board (IRB) of Shalamar Medical and Dental College (SMDC) Lahore. Written informed consent was taken from all participants. The exercise protocol consisted of one session of walking on treadmill for 10 minutes; the cardio-respiratory parameters were taken before and within 6 minutes after performing exercise. After taking informed consent participants were provided with a questionnaire before starting exercise. This questionnaire included self-reported demographic information, information on sports participation and physical activity levels, medical and family history. Height, weight, waist and hip measurements were done and BMI was calculated. Baseline cardiovascular parameters like heart rate, systolic blood pressure (SBP), diastolic blood Pressure (DBP) and oxygen saturation were taken manually in the study subjects. BP was measured before and at the end of exercise. BP measurements were taken by auscultatory method in sitting position using manual Mercury sphygmomanometer. Pulse and oxygen saturation was taken by Pulse Oxymeter before and after the exercise. ECG was performed before and after exercise by using Power Lab. Resting and post exercise electrocardiograms were recorded in recumbent position. Resting and post exercise respiratory rate was measured.

\section{Inclusion Criteria}

Healthy male and female MBBS students of Shalamar Medical \& Dental College.

\section{Exclusion Criteria}

1. Subjects having any heart disease, acute or chronic respiratory infection, or on treatment

2. Subjects with previous history of chest surgery; pregnancy, suffering from diabetes mellitus.

\section{Statistical Analysis}

Statistical analysis was done by SPSS version 21 . Data was represented as Mean $\pm \mathrm{SD}$. Independent " $t$ ' test was used to determine the significance. A $p$ value $<0.05$ is considered significant.

\section{RESULTS}

The study was conducted on 50 medical students of 1st and 2nd year MBBS with mean age of 19.61 \pm 0.63 . Table 1 depicts the anthropometric characteristics of the participants as a whole. The anthropometric characteristics of the participants by gender are shown in Table 2. There was no significant difference in the age of male and female students. Body weight, height, BMI, waist and hip circumference, waist hip ratio and waist height ratio were significantly higher in males compared to females $(\mathrm{p}<0.05)$ (Table 2). 
Table1: Anthropometric Characteristics of Study

Participants

\begin{tabular}{|l|l|}
\hline \multicolumn{1}{|c|}{ Variables } & \multicolumn{1}{c|}{ Mean \pm S.D } \\
\hline $\mathrm{n}$ & 50 \\
\hline Age (year) & $19.61 \pm 0.63$ \\
\hline Weight $(\mathrm{kg})$ & $77.55 \pm 23.83$ \\
\hline Height $(\mathrm{cm})$ & $1.71 \pm 0.100$ \\
\hline BMI $\left(\mathrm{kg} / \mathrm{m}^{2)}\right.$ & $26.42 \pm 6.34$ \\
\hline Waist $(\mathrm{cm})$ & $89.39 \pm 15.90$ \\
\hline Hip $(\mathrm{cm})$ & $105.36 \pm 11.53$ \\
\hline WHR & $0.83 \pm 0.07$ \\
\hline Waist height ratio & $0.51 \pm 0.07$ \\
\hline
\end{tabular}

Table 2: Comparison of Anthropometric Parameters with Respect to Gender

\begin{tabular}{|l|l|l|l|}
\hline Variables & \multicolumn{1}{|c|}{$\begin{array}{c}\text { Male } \\
\text { subjects } \\
\text { mean } \pm \text { S.D }\end{array}$} & $\begin{array}{c}\text { Female } \\
\text { subjects } \\
\text { mean } \pm \text { S.D }\end{array}$ & $\begin{array}{c}\text { p } \\
\text { value }\end{array}$ \\
\hline Age (years) & $19.7 \pm 0.70$ & $19.4 \pm 0.51$ & $>0.05$ \\
\hline $\begin{array}{l}\text { Weight } \\
(\text { Kg) }\end{array}$ & $87.66 \pm 10.83$ & $61.58 \pm 6.93$ & $<0.05^{*}$ \\
\hline Height $(\mathrm{m})$ & $1.77 \pm 0.067$ & $1.62 \pm 0.075$ & $<0.05^{*}$ \\
\hline BMI $\left(\mathrm{kg} / \mathrm{m}^{2}\right)$ & $27.96 \pm 6.70$ & $23.98 \pm 4.97$ & $<0.05^{*}$ \\
\hline Waist $(\mathrm{cm})$ & $96.03 \pm 15.36$ & $78.9 \pm 10.24$ & $<0.05^{*}$ \\
\hline Hip $(\mathrm{cm})$ & $108.5 \pm 11.67$ & $100.3 \pm 9.58$ & $<0.05^{*}$ \\
\hline WHR & $0.87 \pm 0.067$ & $0.77 \pm 0.45$ & $<0.05^{*}$ \\
\hline $\begin{array}{l}\text { Waist } \\
\text { height ratio }\end{array}$ & $0.536 \pm 0.084$ & $0.48 \pm 0.059$ & $<0.05^{*}$ \\
\hline
\end{tabular}

The respiratory rate, respiratory minute volume and tidal volume increased while oxygen saturation decreased significantly after exercise $(\mathrm{p}<0.05)$ in all participants (Table\#3). There was a significant $(p<0.05)$ increase in the respiratory rate from $15.79 \pm 4.17 / \mathrm{min}$ in pre exercise to $21.59 \pm 4.34 / \mathrm{min}$ in post exercise period. Increase in respiratory rate was more in males $(16.80 \pm 5.06 / \mathrm{min})$ as compared to females $(14.21 \pm 0.917 / \mathrm{min})$ and the difference was statistically significant $(\mathrm{p}<0.05) \quad($ Table \#4).
Oxygen saturation decreased significantly from $97.12 \pm 1.033 \%$ to $93.02 \pm 3.59 \%$ in early post exercise period. It was $97.1 \pm 1.26$ in males and $97.15 \pm 0.50$ in females (Table \#4). This difference in decrease of oxygen saturation between males and females was not significant $(p>0.05)$. Tidal volume increased significantly $(<0.05)$ in immediate post exercise period $(1.0 \pm 0.42 \mathrm{~L})$ as compared to pre exercise period $(0.54 \pm 0.27 \mathrm{~L})$. There was significant $(p<0.05)$ increased in Tidal volume up to $1.18 \pm 0.11 \mathrm{~L}$ in females and $1.59 \pm 0.471 \mathrm{~L}$ in males after exercise (Table \#4). Minute respiratory volume increased significantly $(\mathrm{p}<0.05)$ in immediate post exercise period $(30.89$ $\pm 10.06 \mathrm{~L} / \mathrm{min}$ ) as compared to pre exercise period $(11.80 \pm 5.52 \mathrm{~L} / \mathrm{min})$ in all participants. There was no significant increase in minute respiratory volume in males $(12.45 \pm 6.93 \mathrm{~L} / \mathrm{min})$ as compared to females $(10.76 \pm 1.46 \mathrm{~L} / \mathrm{min})$ (Table \#4). Heart rate increased significantly from $91.30 \pm 16.78$ to $136.81 \pm 19.79$ in post exercise period in all participants. The increase in heart rate was more in females $(138.6 \pm 8.22)$ than males $(132 \pm 24.6)$ in the immediate post exercise period (Table \#4). The pre exercise systolic and diastolic blood pressure increase significantly after exercise in all participants (Table\#3). There was a significant post exercise increment in diastolic pressure in males and females (Table \#4). QT intervals pre and postexercise was $0.34 \pm 0.02 \mathrm{sec}$ and $0.33 \pm 0.03 \mathrm{sec}$ in males and $0.35 \pm 0.01$ and $0.29 \pm 0.03 \mathrm{sec}$ in females. QT was significantly $(\mathrm{p}<0.05)$ decreased in postexercise period in females exclusively (Table \#4). Pre and post exercise PR intervals was $0.15 \pm$ $0.04 \mathrm{sec}$ and $0.14 \pm 0.026 \mathrm{sec}$ in males and $0.13 \pm 0.03 \mathrm{sec}$ and $0.14 \pm 4.32 \mathrm{sec}$ in females respectively. The decrease in PR interval was nonsignificant $(p>0.05)$ in both genders. Pre and postexercise QRS durations were found to be $0.07 \pm 0.11 \mathrm{sec}$ and $0.06 \pm 0.001 \mathrm{sec}$ in males and $0.06 \pm 0.007 \mathrm{sec}$ and $0.07 \pm 0.05 \mathrm{sec}$ in females respectively. There was no significant difference observed in post exercise PR and QRS intervals among males and females (Table \#4). 
Table 3: Comparison of Cardio-Respiratory variables before and after exercise in all participants

\begin{tabular}{|l|l|l|l|}
\hline \multicolumn{1}{|c|}{ Variables } & \multicolumn{1}{|c|}{$\begin{array}{c}\text { Before exercise } \\
\mathbf{n = 5 0}\end{array}$} & \multicolumn{1}{|c|}{$\begin{array}{c}\text { After exercise } \\
\mathbf{n = 5 0}\end{array}$} & p value \\
\hline Systolic blood pressure (mmHg) & $118.67 \pm 7.62$ & $132.65 \pm 12.66^{*}$ & $<0.05$ \\
\hline Diastolic blood pressure (mmHg) & $82.34 \pm 7.71$ & $88.46 \pm 7.71^{*}$ & $<0.05$ \\
\hline Heart rate /min & $91.30 \pm 16.78$ & $136.81 \pm 19.79^{*}$ & $<0.05$ \\
\hline Respiratory Rate/min & $15.79 \pm 4.17$ & $21.59 \pm 4.34^{*}$ & $<0.05$ \\
\hline Oxygen Saturation \% & $97.12 \pm 1.033$ & $93.02 \pm 3.59^{*}$ & $<0.05$ \\
\hline Tidal Volume (L) & $0.54 \pm 0.277$ & $1.0 \pm 0.42^{*}$ & $<0.05$ \\
\hline Minute Respiratory volume (L/min) & $11.80 \pm 5.52$ & $30.89 \pm 10.06^{*}$ & $<0.05$ \\
\hline PR interval (sec) & $0.14 \pm 0.03$ & $0.53 \pm 2.69$ & 0.322 \\
\hline QT interval (sec) & $0.352 \pm 0.02$ & $0.31 \pm 0.04^{*}$ & $<0.05$ \\
\hline QRS complex (sec) & $0.067 \pm 0.011$ & $0.070 \pm 0.034$ & 0.64 \\
\hline
\end{tabular}

$\mathrm{p}$ value $<0.05$ was considered statistically significant

Table 4: Comparison of Cardio-Respiratory Variables of Male \& Female Subjects before and after Exercise

\begin{tabular}{|c|c|c|c|c|}
\hline \multirow{2}{*}{ Variables } & \multicolumn{2}{|c|}{ Male Subjects } & \multicolumn{2}{|c|}{ Female subjects } \\
\hline & Before exercise & After exercise & $\begin{array}{c}\text { Before } \\
\text { exercise }\end{array}$ & $\begin{array}{c}\text { After } \\
\text { exercise }\end{array}$ \\
\hline Respiratory Rate /min & $16.80 \pm 5.06$ & $23.4 \pm 4.34^{*}$ & $14.21 \pm 0.91$ & $18.73 \pm 2.42 *$ \\
\hline Heart rate /min & $83.63 \pm 17.52$ & $132 \pm 24.6^{*}$ & $103.4 \pm 1.92$ & $138.6 \pm 8.22 *$ \\
\hline $\begin{array}{l}\text { Systolic Blood Pressure } \\
(\mathrm{mmHg})\end{array}$ & $118 \pm 8.97$ & $134 \pm 15.78^{*}$ & $118 \pm 5.01$ & $129 \pm 2.50 *$ \\
\hline $\begin{array}{l}\text { Diastolic blood pressure } \\
(\mathrm{mmHg})\end{array}$ & $84.5 \pm 8.93$ & $88.16 \pm 9.60^{*}$ & $78.94 \pm 3.15$ & $88.94 \pm 3.15^{*}$ \\
\hline Oxygen Saturation (\%) & $97.1 \pm 1.26$ & $95.1 \pm 2.61^{*}$ & $97.15 \pm 0.50$ & $89.73 \pm 2.20 *$ \\
\hline Tidal Volume (L) & $0.74 \pm 0.34$ & $1.59 \pm 0.471 *$ & $0.75 \pm 0.10$ & $1.18 \pm 0.11^{*}$ \\
\hline $\begin{array}{l}\text { Minute Respiratory volume } \\
\text { (L/min) }\end{array}$ & $12.45 \pm 6.93$ & $36.28 \pm 8.48^{*}$ & $10.76 \pm 1.46$ & $22.40 \pm 5.43 *$ \\
\hline PR interval (sec) & $0.15 \pm 0.04$ & $0.149 \pm 0.026$ & $0.13 \pm 0.03$ & $0.14 \pm 4.32$ \\
\hline QT interval (sec) & $0.349 \pm 0.028$ & $0.336 \pm 0.034$ & $0.35 \pm 0.01$ & $0.29 \pm 0.03 *$ \\
\hline QRS complex (sec) & $0.071 \pm 0.11$ & $0.068 \pm 0.0018$ & $0.06 \pm 0.007$ & $0.074 \pm 0.05$ \\
\hline
\end{tabular}

p value $<0.05$ was considered statistically significant 


\section{DISCUSSION}

The function of the respiratory system is influenced by multiple factors like nervous system, power of respiratory muscles, and dimensions of lung ${ }^{6}$. Latest advances in sports physiology revealed significant positive association of exercise with respiratory parameters ${ }^{7}$. However, few studies have reported non-significant associations ${ }^{8}$. The results of this study revealed changes in the cardiorespiratory parameters in immediate post exercise period. The respiratory rate, respiratory minute volume and tidal volume increase while oxygen saturation decrease significantly after exercise $(p<0.05)$ in all participants in the current study. Tripton reported a wide range of alterations in the tidal volume and respiratory rate in his article ${ }^{9}$ Muscular exercise increases the respiratory rate and depth in order to improve FVC, the availability of oxygen and the rate of diffusion through respiratory membrane ${ }^{10}$. The study conducted by Fatima showed decrease in oxygen saturation after exercise as compared to pre exercise period ${ }^{1}$ while, Anupama reported high oxygen saturation in the exercising adults as compared to non-exercising adults ${ }^{11}$. Luiz mentioned various studies in his meta-analysis that also reported post exercise increment in tidal volume $\&$ respirator rate ${ }^{12}$. These results bear resemblance with the results of the current study. The increase in respiratory minute volume during moderate muscular exercise is due to nervous impulses generated from the exercising muscles, and the humoral agents produced during exercise that act directly or indirectly on the respiratory center $^{13}$. The heart rate increased significantly in post exercise period in all participants. The increase in heart rate was more in females in the immediate post exercise period. Significant increase in heart rate than baseline after performing exercise is also observed in other studies as well ${ }^{4}$. The pre exercise Systolic and diastolic blood pressure increase significantly after exercise in all participants. These results resemble the results of the study conducted by Forjaz who reported a non-significant increase in systolic and a significant increase in diastolic pressure after exercise $^{14}$. BP changes during normal exercise are brought about by the interaction between increased cardiac output and reduced total peripheral vascular resistance ${ }^{15}$. The increase in diastolic blood pressure during low intensity exercise is an independent predictor of future cardiovascular mortality and morbidity ${ }^{16}$. As far as ECG is concerned, QT interval decreased significantly only in females; however changes in PR interval and QRS complex were not significant. Ogedengbe mentioned increase in QT interval in both males and females in his study ${ }^{17}$ while Hill and Timmys found shortening of PR, QT intervals and QRS complex, these results resemble with the results of the current study ${ }^{18}$.

\section{CONCLUSION}

Decrease in QT interval in females might be due to more increase in heart rate in females after exercise. Conclusions drawn from the study revealed that cardio-respiratory parameters alter during early post exercise period in healthy adults. The respiratory rate, respiratory minute volume and tidal volume increased while oxygen saturation decreased significantly after exercise. Heart rate and blood pressure increased significantly both in male and female subjects. QT interval decreased significantly only in females; however changes in PR interval and QRS complex were not significant.

\section{REFERENCES}

1. Fatima SS, Rehman R, Khan YS. Physical activity and its effect on forced expiratory volume. J Pak Med Assoc. 2013 Mar 1;63(3):310-2.

2. Waschki B, Kirsten A, Holz O, Müller KC, Meyer $\mathrm{T}$, Watz $\mathrm{H}$, Magnussen H. Physical activity is the strongest predictor of all-cause mortality in patients with COPD: a prospective cohort study. Chest. 2011 Aug 1;140(2):331-42.

3. Cheng YJ, Macera CA, Addy CL, Sy FS, Wieland D, Blair SN. Effects of physical activity on exercise tests and respiratory function. British journal of sports medicine. 2003;37(6):521-8. 
4. Javorka M, Zila I, Balharek T, Javorka K. Heart rate recovery after exercise: relations to heart rate variability and complexity. Brazilian Journal of Medical and Biological Research. 2002 Aug;35(8):991-1000.

5. Gowdhami B, Abirami V, Padmavathi R, Thanasekaran V, Rajagopalan B. Effect of Sub Maximal Exercise Test on Cardiovascular Parameters in Young Obese Adults. Int. J. Pure App. Biosci. 2015;3(4):109-15.

6. Kenney WL, Wilmore J, Costill D. Physiology of sport and exercise 6th edition. Human kinetics; 2015 Mar 30.

7. Tharion EL, Samuel PR, Rajalakshmi R, Gnanasenthil G, Subramanian RK. Influence of deep breathing exercise on spontaneous respiratory rate and heart rate variability: a randomised controlled trial in healthy subjects. Indian J Physiol Pharmacol. 2012;56(1):80-7.

8. Prakash S, Meshram S, Ramtekkar U. Athletes, yogis and individuals with sedentary lifestyles; do their lung functions differ?. Indian journal of physiology and pharmacology. 2007 Jan 20;51(1):76.

9. Tipton MJ, Harper A, Paton JF, Costello JT. The human ventilatory response to stress: rate or depth?. The Journal of physiology. 2017 Sep 1;595(17):5729-52.

10. Hall JE. Guyton and Hall textbook of medical physiology e-Book. Elsevier Health Sciences; 2010 Jul 19. 471p.

11. Anupama N, Kini RD, Sharma MV, Bhagyalaksmi K, Nayanatara AK, Shetty S, Panikulam EJ. Effect of exercise on oxygen saturation and heart rate in healthy young adults of different body mass index. Research Journal of Pharmaceutical, Biological and Chemical Sciences. 2016 Sep 1;7(5):594-7.

12. Junior LC, Pillay JD, van Mechelen W, Verhagen E. Meta-analyses of the effects of habitual running on indices of health in physically inactive adults. Sports medicine. 2015 Oct 1;45(10):1455-68.
13. Mondal H, Mishra SP. Effect of BMI, body fat percentage and fat free mass on maximal oxygen consumption in healthy young adults. Journal of clinical and diagnostic research: JCDR. 2017 Jun;11(6):CC17.

14. Forjaz CL, Matsudaira Y, Rodrigues FB, Nunes N, Negrão CE. Post-exercise changes in blood pressure, heart rate and rate pressure product at different exercise intensities in normotensive humans. Brazilian Journal of Medical and Biological Research. 1998 Oct;31(10):1247-55.

15. Lavie CJ, Arena R, Swift DL, Johannsen NM, Sui X, Lee DC, Earnest CP, Church TS, O'keefe JH, Milani RV, Blair SN. Exercise and the cardiovascular system: clinical science and cardiovascular outcomes. Circulation research. 2015 Jul 3;117(2):207-19.

16. Fletcher GF, Ades PA, Kligfield P, Arena R, Balady GJ, Bittner VA, Coke LA, Fleg JL, Forman DE, Gerber TC, Gulati M. Exercise standards for testing and training: a scientific statement from the American Heart Association. Circulation. 2013 Aug 20;128(8):873-934.

17. Ogedengbe JO, Adelaiye AB, Kolawole OV. Effects of exercise on PR intervals, QRS durations and QTC intervals in male and female students of University of Abuja. JPMA-Journal of the Pakistan Medical Association. 2012 Mar 1;62(3):273.

18. Hill J, Timmis A. ABC of clinical electrocardiography: Exercise tolerance testing. BMJ: British Medical Journal. 2002 May 4;324(7345):1084.

\section{Corresponding Author:}

Dr. Ambreen Khalid

Department of Physiology

Shalamar Medical \& Dental College, Lahore

Email:ambreenkr@yahoo.com 